\title{
Intrathecal baclofen infusion and subsequent orthopedic surgery in patients with spastic cerebral palsy
}

\author{
Peter C. Gerszten, M.D., A. Leland Albright, M.D., and Graham F. Johnstone, M.D.
}

Departments of Neurosurgery and Orthopedic Surgery, Children's Hospital of Pittsburgh, University of Pittsburgh School of Medicine, Pittsburgh, Pennsylvania

Intrathecal baclofen infusion (IBI) is an effective treatment for spasticity secondary to cerebral palsy (CP). The authors retrospectively reviewed the need for orthopedic surgery of the lower extremities in 48 patients with spastic $\mathrm{CP}$ who were treated with IBI. Forty pumps were placed in patients suffering from spastic quadriplegia (84\%) and eight $(16 \%)$ in patients with spastic diplegia. The patients' ages ranged from 5 to 43 years (mean 15 years). The mean follow-up period was 53 months (range 22-94 months). The mean baclofen dosage was $306 \mu \mathrm{g} /$ day (range $25-1350 \mu \mathrm{g} /$ day). At the time of pump placement, subsequent orthopedic surgery was planned in 28 patients $(58 \%)$; however, only $10(21 \%)$ underwent orthopedic surgery after IBI therapy. In all 10 cases, the surgical procedure was planned at the time of initial evaluation for IBI therapy. In the remaining 18 patients, who did not subsequently undergo their planned orthopedic operation, it was believed that their lower-extremity spasticity had improved to the degree that orthopedic intervention was no longer indicated. In addition, although six patients had undergone multiple orthopedic operations before their spasticity was treated, no patient required more than one orthopedic operation after IBI treatment for their spasticity. The authors conclude that IBI for treatment of spastic CP reduces the need for subsequent orthopedic surgery for the effects of lower-extremity spasticity. In patients with spastic CP and lower-extremity contractures, spasticity should be treated before orthopedic procedures are performed.

\section{Key Words * baclofen * cerebral palsy * orthopedic operation * spasticity}

Cerebral palsy (CP) affects approximately 750,000 individuals in the United States, with an incidence of 1.5 to 2.5 per 1000 live births.[1,19] Given the increased survival rates among the lower-birth-weight groups, the rate of CP is actually increasing worldwide. The National Institutes of Health has estimated societal costs at $\$ 5$ billion for care of individuals with $\mathrm{CP}$ who are younger than 18 years of age.[1]

Cerebral palsy is characterized by abnormalities of movement, including spasticity, athetosis, chorea, dystonia, and ataxia. Two-thirds of the patients with $\mathrm{CP}$ have spasticity. In recent decades, neurosurgical procedures such as selective dorsal rhizotomy (SDR) have been demonstrated to reduce lower-extremity spasticity of cerebral origin.[4,9,11,20,22,28] More recently, intrathecal baclofen infusion (IBI) has been shown to be an effective treatment for spasticity secondary to $\mathrm{CP}$ and traumatic brain injury.[2,3,6,8,10,12-14,16,18,23-25,28,30] 
In the past, cerebral spasticity has often been treated primarily by physical therapists in an attempt to maintain range of motion and improve function. Operations on the lower extremities are frequently required in this population. The orthopedic consequences resulting from spasticity include contractures and dislocations.[9,26] Orthopedic procedures include tendon releases and lengthenings and osteotomies. These operations often need to be repeated if the underlying spasticity is not reduced.

Orthopedic surgery and spasticity-reducing procedures have a preventive value because they may reduce the incidence of progressive orthopedic deformities that often occur in patients with spastic

CP. $[9,20,26,32]$ Such progressive deformities require further orthopedic surgical intervention. A recent study found that early SDR reduces the need for subsequent orthopedic surgery in children with spastic CP.[9] The current investigation was undertaken to test the hypothesis that IBI therapy also reduces the need for subsequent orthopedic surgery in this population.

\section{CLINICAL MATERIAL AND METHODS}

This study involved a retrospective analysis of 48 patients with spastic CP who underwent IBI therapy during the period from 1989 to 1995 . The patients' ages ranged from 5 to 43 years (mean 15 years). The mean follow-up period was 53 months (at least 24 months in all cases). Patients with moderate or severe spasticity of cerebral origin were examined by a multidisciplinary team in the Spasticity Clinic at the Children's Hospital of Pittsburgh. The diagnoses included eight cases of spastic diplegia (16\%) and 40 cases of spastic quadriplegia (84\%).

Patients were admitted for a screening trial to determine if single IBI doses reduced their spasticity. Patients whose average lower-extremity muscle tone decreased by 1 or more according to the Ashworth scale[5] after any IBI dose (50-, 75-, or 100- $\mu$ g bolus injection) were considered to have a clinically significant response and were offered implantation of a programmable subcutaneous pump for continuous IBI (Medtronic, Inc., Minneapolis, MN). The technique for pump insertion has been described elsewhere.[1] The mean baclofen dosage was $306 \mathrm{mg} /$ day (range 25-1350 $\mu \mathrm{g} /$ day).

The goal of IBI therapy is not to abolish spasticity but rather to decrease it to improve range of motion, facilitate movement, reduce energy expenditure, and reduce the risk of contractures. After pump implantation, IBI dosages were increased during the 1 st week until the mean lower-extremity muscle tone was perceptibly reduced and then increased again during the follow-up period, titrating the IBI dosage to the desired clinical response. Most patients received physical therapy 2 to 5 days per week for the first 6 months postoperatively and 1 to 3 days per week for the next 6 to 18 months.

Documentation of orthopedic surgery performed before and after baclofen pump placement was obtained from preoperative clinical assessments and postoperative follow-up visits. Orthopedic operations were categorized as adductor releases, heel-cord releases, iliopsoas releases, hamstring releases, femoral osteotomies, ankle-foot osteotomies, or "other" operations that included repair of quadriceps muscle releases, tibial osteotomies, and hip reconstructions.

At the time the decision was made to place the baclofen pump, an orthopedic surgeon (G.F.J.) documented the anticipated need for orthopedic surgical intervention for lower-extremity contractures and/or bone deformities. The criteria for surgical intervention included radiographic evidence of bone abnormalities, degree of spasticity, findings on physical examination (such as hip subluxation, joint range of motion, and presence of contractures), and functional limitations of these findings. In all of these cases, the patients and/or families were informed of the possible need for future surgical intervention. All 
patients received regular follow-up care from both the neurosurgery and orthopedic surgery services and their responses to IBI therapy and the status of their lower-extremity deformities were evaluated.

\section{RESULTS}

Twenty-nine patients $(60 \%)$ had undergone at least one orthopedic procedure before baclofen pump placement. The mean patient age at time of the first orthopedic operation was 8 years (range 2-19 years). The number and types of procedures performed are shown in Table 1 . Heel-cord release was by far the most common procedure (42\%), followed by hamstring release (33\%) and adductor release (31\%).

\begin{tabular}{|c|c|c|c|c|}
\hline \multicolumn{5}{|c|}{$\begin{array}{c}\text { TABLE } 1 \\
\text { NUMBER, PERCEN TAGE, AND MEAN AGE OF } 48 \text { PATIENTS WITH CP WHO UNDERWENT } \\
\text { ORTHOPED K SURGERY BV PROCEDURE TY PE` }\end{array}$} \\
\hline \multirow[b]{2}{*}{$\begin{array}{l}\text { Type of } \\
\text { surgery }\end{array}$} & \multicolumn{2}{|c|}{ Before IBI } & \multicolumn{2}{|c|}{ After I Bl } \\
\hline & $\begin{array}{c}\text { No. of } \\
\text { Patiens (\%) }\end{array}$ & $\begin{array}{c}\text { Mean } A_{g e} \\
\text { Yrst (range) }\end{array}$ & $\begin{array}{c}\text { No. of } \\
\text { Patiens (\%) }\end{array}$ & $\begin{array}{l}\text { Mean } A_{g e} \\
\text { Yrst (range) }\end{array}$ \\
\hline $\begin{array}{l}\text { heel cord release } \\
\text { hamstring release } \\
\text { iliopsos release } \\
\text { adductor release } \\
\text { femoral osteotomy } \\
\text { anklefoot } \\
\text { other } \\
\text { total no. of surgeries }\end{array}$ & $\begin{array}{c}20(42) \\
16(33) \\
8(17) \\
16(33) \\
6(12) \\
1(2) \\
5(8) \\
29(60)\end{array}$ & $\begin{array}{r}8(2-13) \\
11(3-19) \\
11(2-21) \\
9(2-19) \\
10(4-15) \\
10 \\
8(6-16) \\
8(2-19)\end{array}$ & $\begin{array}{l}1(2) \\
5(8) \\
1(2) \\
1(2) \\
7(15) \\
0 \\
0 \\
10(21)\end{array}$ & $\begin{array}{l}7 \\
12(7-19) \\
19 \\
19 \\
10(5-19) \\
N \ddot{N} \\
\text { NA } \\
15(5-19)\end{array}$ \\
\hline
\end{tabular}

Six patients underwent two separate operations for lower-extremity orthopedic deformities before IBI pump placement. The ages at surgery and procedures performed in this group of patients are shown in Table 2. A single operative session included all orthopedic procedures performed on a single date. If a patient underwent further or repeated orthopedic operations at a later date, these were considered to be a separate operative sessions.

\begin{tabular}{|c|c|c|}
\hline AGES AND & $\begin{array}{l}\text { PES OF SL } \\
\text { ORTHOPE }\end{array}$ & $\begin{array}{l}\text { TABLE } 2 \\
\text { IN PATIENTS WHO UNDERWENT MORE THAN TWO } \\
\text { OCEDURES PR OR TO IBI THERAPY }\end{array}$ \\
\hline $\begin{array}{l}\text { Case } \\
\text { No. }\end{array}$ & $\begin{array}{c}\text { Age [ys] } \\
\text { at Op }\end{array}$ & Type of Sugery \\
\hline 1 & 6 & heel-oord release \\
\hline & 15 & hamstring, iliopsoas, \& adductor releases \\
\hline 2 & 10 & hamstring $\&$ adductor releases \\
\hline & 21 & iliopsoas release \\
\hline 3 & 5 & heel-oord $\&$ adductor releases \\
\hline & & hamstring release \\
\hline 4 & 4 & heel-oond release \\
\hline & 10 & adductor release \\
\hline 5 & 7 & adductor release \\
\hline & 9 & heel-oord release \\
\hline 6 & 3 & heel-oord \& hamstring releases \\
\hline & 6 & adductor \& Illopsoas releases \\
\hline
\end{tabular}

Subsequent orthopedic surgery was planned at the time of pump placement in 28 patients; however, only 10 patients ( $36 \%$ of those in whom surgery was planned) eventually underwent orthopedic surgery after 
IBI therapy. The types of procedures performed in those patients who underwent orthopedic surgery after pump placement are also shown in Table 1.

Further analysis of this group of 10 patients revealed that in all cases the surgical procedure was planned at the time of initial evaluation for IBI therapy. The mean age for this group of patients was 10 years (range 5-19 years). Of the 10 operations, eight were performed within 12 months and two within 18 months of pump placement. The first orthopedic procedure followed pump implantation in four of the 10 patients. No patient who underwent orthopedic surgery after IBI therapy required a second operation.

In this group of 10 patients, the most commonly performed procedure was a femoral osteotomy, followed by hamstring release (Table 2). The mean age of the four patients in whom the first orthopedic procedure was performed after IBI therapy was 10 years (range 7-19 years). All of these four patients underwent either hamstring release or femoral osteotomy (Table 3 ).

\begin{tabular}{|c|c|c|}
\hline \multicolumn{3}{|c|}{$\begin{array}{c}\text { TABLE } 3 \\
\text { AGES AND TV PES OF SURGERV IN PATIENTS WHO UNDERWENT } \\
\text { THER FIRST ORTHOPED K OPERATION AFTER IBI THERAPV } \\
\end{array}$} \\
\hline $\begin{array}{l}\text { Case } \\
\text { No. }\end{array}$ & $\begin{array}{c}\text { Age (yrs) } \\
\text { at Op }\end{array}$ & Type of Sugery \\
\hline 1 & 7 & hamstring release \\
\hline 2 & & femoral osteotomy \\
\hline 3 & 8 & hamstring release, femoral osteotom y \\
\hline 4 & 19 & hamstring release, femoral osteotom y \\
\hline
\end{tabular}

In the remaining $18(64 \%)$ of 28 patients who did not subsequently undergo their planned orthopedic surgery, the same orthopedic surgeon believed that orthopedic intervention was no longer required. The decision was based on the degree of diminution of contractures such that joint range of motion had improved and no significant functional limitations were present. Refusal to undergo recommended surgery was not an issue among this group of 18 patients. Although improvement in spasticity does not result directly in improvement of lower-extremity contractures, dislocations, or deformities, it may result in reduction of apparent fixed contractures that in reality were dynamic contractures.

Eleven patients (23\%) required a revision of their pump for malfunction secondary to catheter-related problems, including catheter fracture and catheter dislocation. The initial thin-walled intrathecal catheter has been redesigned, and no further fracture has occurred with the current, thicker-walled catheter.

\section{DISCUSSION}

Spasticity is defined as a velocity-dependent increase in the stretch reflex determined by passively flexing and extending muscle groups across a joint.[29] Neurosurgical operations to relieve spasticity have been in use for more than a century, but most have achieved only marginal success.[29] During the 1980s, SDRs were modified and popularized for the treatment of lower-extremity spasticity.[4,9,11,20-22,29] In addition to surgical intervention, a variety of oral medications have been used to treat spasticity, including dantrolene, diazepam, and baclofen. Baclofen is an agonist of the inhibitory neurotransmitter gamma-aminobutyric acid.[2] and acts at the spinal cord level, primarily by inhibiting the release of excitatory neurotransmitters. Baclofen is lipophilic and crosses the blood-brain barrier poorly, and therefore is ideally administered intrathecally. It works in essence as a substitute for gamma-aminobutyric acid, which should be released by the descending inhibitory impulses.[1,29] 
In 1984, Penn and Kroin[24] first reported that a bolus injection of baclofen could transiently reduce spasticity in patients with spinal cord injury. Later this work was extended to involve long-term IBI by means of an implanted drug pump.[23,25] More recently, IBI has been shown to be an effective treatment modality for spasticity secondary to both $\mathrm{CP}$ and traumatic brain injury.[2,3,6,8,10,12-14,16,18,28,30,31]

In spite of the effectiveness of IBI therapy in relieving spasticity, a substantial proportion of children with spastic $\mathrm{CP}$ develop contractures before their spasticity is treated and require orthopedic surgery to correct the musculoskeletal effects of spasticity. As many as $28 \%$ of children with spastic CP develop hip dislocations,[27] and 20\% require operations for spastic internal femoral rotation.[15] Twenty-five percent of children with spastic $\mathrm{CP}$ will require heel-cord release or lengthening for talipes equinus deformity.[7] One prospective study of 74 children with spastic CP found that $61 \%$ had undergone orthopedic operations by 8 years of age.[33] Between $10 \%$ and $20 \%$ of children with spastic CP require two or more separate orthopedic operations. $[9,17]$

Many variables influence the rate of orthopedic operations performed in patients with spastic CP, including the severity of the spasticity, the joints involved, and the age of the patient.[9] In addition, there are differences among orthopedic surgeons as to their beliefs about the optimum age at which a patient should undergo a surgical intervention, as well as the surgical indications for each of the different procedures.[26] For these reasons, no historical control exists for the rate of orthopedic surgery in patients with spastic CP.

In study by Chicoine, et al.,[9] the authors examined the effects of SDR on rates of lower-extremity orthopedic surgery in 178 children with CP. This was the first such systematic analysis of the rates of orthopedic surgery for a large population of children with spastic CP. They found that children undergoing SDR at a younger age (between 2 and 4 years) were less likely to require orthopedic surgery for heel-cord, hamstring, and adductor releases. If the reduced need for subsequent orthopedic procedures of the lower extremity was due to improvement in lower-extremity spasticity resulting from SDR, then it was postulated that improvement in spasticity as a result of IBI therapy would likewise decrease the need for subsequent orthopedic intervention.

We observed that of our 48 patients who underwent IBI pump placement, $60 \%$ had previously undergone at least one orthopedic procedure, a rate similar to those in other reported series.[9,33] The most common procedures were heel-cord, hamstring, and adductor releases. Ten patients $(21 \%)$ in our series subsequently underwent an orthopedic procedure after IBI therapy. Of note, however, is that 28 patients (58\%) had future orthopedic surgery planned at the time of pump placement. It was believed that the IBI would improve the outcome of the orthopedic surgery by diminishing the incidence of postoperative contractures. In the 18 patients who did not undergo their planned orthopedic surgery, it was believed that their lower-extremity spasticity had improved after IBI therapy such that orthopedic intervention was no longer required.

It is our policy to avoid orthopedic surgery at the time of pump placement which might increase the risk of postoperative pump infection. In addition, IBI therapy might reduce the extent of orthopedic surgery needed or eliminate the need for future orthopedic surgical intervention altogether. This may reflect the decision of the orthopedic surgeon to postpone orthopedic surgery until the child's outcome from IBI therapy is more clearly defined.

Of the ten patients who did undergo orthopedic surgery after IBI pump placement, the surgery was 
planned in all cases at the time of initial evaluation for IBI therapy. All procedures were performed within 18 months of pump placement. No patient who underwent orthopedic surgery after IBI therapy required a second operation. The most commonly performed orthopedic procedure after IBI administration was a femoral osteotomy (seven of 10 patients). This contrasts with the frequency of femoral osteotomy in the pre-IBI group (six of 29 patients). This difference likely reflects the fact that nonoperative treatment has historically been unsuccessful in achieving the objectives of proper treatment of the deformity, the goal of surgery being to increase stability of the hip.[15,32]

Given that our study population represents a diverse group of patients with a wide range of ages, it cannot be determined if IBI therapy at an earlier age has greater benefit over pump placement at a later age for a reduction in the development of lower-extremity orthopedic deformities that result from spasticity. However, given the significant number of patients who avoided subsequent orthopedic surgery after IBI therapy, one might infer that this would indeed be the case. It is not known how many of the patients who avoided orthopedic procedures may require surgery in the future.

The major limitation of this study is the lack of a simultaneous control group undergoing similar physical therapy intervention. The potential for such bias is a threat to both the internal and external validity of this study. In addition, no control group from the literature is currently available for comparison with our rates of subsequent orthopedic surgery. However, comparisons among patients within the study group receiving similar surgical and nonsurgical interventions served to minimize this selection bias. Longer follow-up intervals and larger study populations followed prospectively will help to define further the role of IBI therapy in the reduction of need for orthopedic intervention.

From this series of 48 patients with spastic CP who underwent IBI pump placement, we conclude that IBI therapy reduces the need for subsequent orthopedic surgery for the effects of lower-extremity spasticity and virtually eliminates the need for multiple orthopedic operations. It is appropriate that patients with spastic CP and significant lower-extremity contractures requiring surgical intervention should undergo evaluation for spasticity reduction before orthopedic procedures are performed.

\section{References}

1. Albright AL: Baclofen in the treatment of cerebral palsy. J Child Neurol 11:77-83, 1996

2. Albright AL, Barron WB, Fasick MP, et al: Continuous intrathecal baclofen infusion for spasticity of cerebral origin. JAMA 270:2475-2477, 1993

3. Albright AL, Cervi A, Singletary J: Intrathecal baclofen for spasticity in cerebral palsy. JAMA 265:1418-1422, 1991

4. Arens LJ, Peacock WJ, Peter J: Selective posterior rhizotomy: a long-term follow-up study. Childs Nerv Syst 5:148-152, 1989

5. Ashworth B: Preliminary trial of carisoprodol in multiple sclerosis. Practitioner 192:540-542, 1964

6. Azouvi P, Mane M, Thiebaut JB, et al: Intrathecal baclofen administration for control of severe spinal spasticity: Functional improvement and long-term follow-up. Arch Phys Med Rehabil 77:35-39, 1996

7. Bennet GC, Rang M, Jones D: Varus and valgus deformities of the foot in cerebral palsy. Dev Med Child Neurol 24:499-503, 1982 
8. Campbell SK, Almeida GL, Penn RD, et al: The effects of intrathecally administered baclofen on function in patients with spasticity. Phys Ther 75:352-362, 1995

9. Chicoine MR, Park TS, Kaufman BA: Selective dorsal rhizotomy and rates of orthopedic surgery in children with spastic cerebral palsy. J Neurosurg 86:34-39, 1997

10. Coffey RJ, Cahill D, Steers W, et al: Intrathecal baclofen for intractable spasticity of spinal origin: results of a long-term multicenter study. J Neurosurg 78:226-232, 1993

11. Fasano VA, Urciuoli R, Broggi G, et al: New aspects in the surgical treatment of cerebral palsy. Acta Neurochir Suppl 24:53-57, 1977

12. Latash ML, Penn RD, Corcos DM, et al: Effects of intrathecal baclofen on voluntary motor control in spastic paresis. J Neurosurg 72:388-392, 1990

13. Lazorthes Y, Sallerin-Caute B, Verdie JC, et al: Chronic intrathecal baclofen administration for control of severe spasticity. J Neurosurg 72:393-402, 1990

14. Loubser PG, Narayan RK, Sandin KJ, et al: Continuous infusion of intrathecal baclofen: long-term effects on spasticity in spinal cord injury. Paraplegia 29:48-64, 1991

15. Majestro TC, Frost HM: Cerebral palsy. Spastic internal femoral torsion. Clin Orthop 79:44-56, 1971

16. Meythaler JM, Steers WD, Tuel SM, et al: Intrathecal baclofen in hereditary spastic paraparesis. Arch Phys Med Rehabil 73:794-797, 1992

17. Norlin R, Tkaczuk H: One-session surgery for correction of lower extremity deformities in children with cerebral palsy. J Pediatr Orthop 5:208-211, 1985

18. Ordia JI, Fischer E, Adamski E, et al: Chronic intrathecal delivery of baclofen by a programmable pump for the treatment of severe spasticity. J Neurosurg 85:452-457, 1996

19. Paneth N, Kiely J: The frequency of cerebral palsy: a review of population studies in industrialized nations since 1950, in Stanley FJ, Alberman ED (eds): The Epidemiology of the Cerebral Palsies:

Clinics in Developmental Medicine. Philadelphia: JB Lippincott, 1984, pp 35-45

20. Park TS, Owen JH: Surgical management of spastic diplegia in cerebral palsy. N Engl J Med 326:745-749, 1992

21. Park TS, Vogler GP, Phillips LH II, et al: Effects of selective dorsal rhizotomy for spastic diplegia on hip migration in cerebral palsy. Pediatr Neurosurg 20:43-49, 1994

22. Peacock WJ, Arens LJ, Berman B: Cerebral palsy spasticity. Selective posterior rhizotomy. Pediatr Neurosci 13:61-66, 1987

23. Penn RD: Intrathecal baclofen for spasticity of spinal origin: seven years of experience. J Neurosurg 77:236-240, 1992

24. Penn RD, Kroin JS: Intrathecal baclofen alleviates spinal cord spasticity. Lancet 1:1078, 1984 (Letter) 
25. Penn RD, Savoy SM, Corcos D, et al: Intrathecal baclofen for severe spinal spasticity. N Engl J Med 320:1517-1521, 1989

26. Pettitt B: Surgery of the lower extremity in cerebral palsy: considerations and approaches. Arch Phys Med Rehabil 57:443-447, 1976

27. Samilson RL, Tsou P, Aamoth G, et al: Dislocation and subluxation of the hip in cerebral palsy. Pathogenesis, natural history and management. J Bone Joint Surg (Am) 54:863-873, 1972

28. Shetter AG: Intrathecal baclofen in the treatment of spasticity of spinal origin: rationale, surgical techniques, and patient monitoring. Perspect Neurol Surg 4:109-122, 1993

29. Shetter AG: The neurosurgical treatment of spasticity. Neurosurg Q 6:194-207, 1996

30. Steinbok P, Armstrong R, Farrell K, et al: Intrathecal baclofen for treatment of spasticity in children: report of nine cases. Can J Neurol Sci 18:232, 1991

31. Van Hemert JCJ: A double-blind comparison of baclofen and placebo in patients with spasticity of cerebral origin, in Feldman RG, Young RR, Koella WP (eds): Spasticity: Disordered Motor Control. Chicago: Year Book Medical, 1980, pp 41-49

32. Vidal J, Deguillaume P, Vidal M: The anatomy of the dysplastic hip in cerebral palsy related to prognosis and treatment. Int Orthop 9:105-110, 1985

33. Watt JM, Robertson CMT, Grace MGA: Early prognosis for ambulation of neonatal intensive care survivors with cerebral palsy. Dev Med Child Neurol 31:766-773, 1989

Manuscript received December 12, 1997.

Accepted in final form December 23, 1997.

Address reprint requests to: A. Leland Albright, M.D., Department of Neurosurgery, Children's Hospital of Pittsburgh, 375 Fifth Avenue, Pittsburgh, Pennsylvania 15213.

Click here to view commentary on this article. 